\title{
Lobar Collapse Therapy Using Endobronchial Valves as a New Complementary Approach to Treat Cavities in Multidrug-Resistant Tuberculosis and Difficult-to-Treat Tuberculosis: A Case Series
}

\author{
Lorenzo Corbetta $^{a, b}$ Ariela Tofani ${ }^{a, b}$ Flavio Montinaro ${ }^{b}$ Lucio Michieletto ${ }^{c}$ \\ Loris Ceron $^{c}$ Chiara Moroni ${ }^{b}$ Pier Giorgio Rogasi ${ }^{b}$ \\ ${ }^{\mathrm{a}}$ Department of Experimental and Clinical Medicine, University of Florence, and ${ }^{\mathrm{b} C a r e g g i}$ University Hospital, \\ Florence, and 'Ospedale dell'Angelo, Venice, Italy
}

\section{Key Words}

Multidrug-resistant tuberculosis - Extensively drug-resistant tuberculosis · Difficult-to-treat tuberculosis · Lobar collapse . Endobronchial valves

\begin{abstract}
Background: The poor treatment outcomes of multidrugresistant tuberculosis (TB) and the emergence of extensively drug-resistant TB and extremely and totally drug-resistant TB highlight the urgent need for new antituberculous drugs and other adjuvant treatment approaches. Objectives: We have treated cavitary tuberculosis by the application of endobronchial one-way valves (Zephyr ${ }^{\circledR}$; Pulmonx Inc., Redwood City, Calif., USA) to induce lobar volume reduction as an adjunct to drug treatment. This report describes the feasibility, effectiveness and safety of the procedure. Methods: Patients with severe lung destruction, one or more cavities or those who were ineligible for surgical resection and showed an unsatisfactory response to standard drug treatments were enrolled. During bronchoscopy, endobronchial valves were implanted in the lobar or segmental bronchi in order to induce atelectasis and reduce the cavity size. Results: Four TB patients and 1 patient with atypical mycobacteriosis were treated. The mean patient age was 52.6 years.
\end{abstract}

\begin{tabular}{ll}
\hline KARGER & $\begin{array}{l}\text { (c) 2016 The Author(s) } \\
\text { Published by S. Karger AG, Basel } \\
\text { 0025-7931/16/0925-0316 } \$ 39.50 / 0\end{array}$ \\
E-Mail karger@karger.com & This article is licensed under the Creative Commons Attribution- \\
www.karger.com/res & NonCommercial-NoDerivatives 4.0 International License (CC BY- \\
& NC-ND) (http://www.karger.com/Services/OpenAccessLicense). \\
& Usage and distribution for commercial purposes as well as any dis- \\
tribution of modified material requires written permission.
\end{tabular}

Complete cavity collapses were observed on CT scans in 4 of the 5 cases. All patients showed improvements in their clinical status, and sputum smears became negative within 3-5 months. There were no severe short- or long-term complications. The valves were removed in 3 of the 5 patients after 8 months on average; there was no relapse after 15 months of follow-up. Conclusion: These data suggest that endobronchial valves are likely to be useful adjuncts to the treatment of therapeutically difficult patients. More data are required to confirm our findings.

(C) 2016 The Author(s) Published by S. Karger AG, Basel

\section{Introduction}

In the 1880s, Dr. Carlo Forlanini devised an apparatus to create artificial pneumothorax in patients as treatment for pulmonary tuberculosis. The apparatus brought air into the pleural space using a Saugmann pneumothorax needle. A water manometer measured the pleural pressure and air volume [1] (fig. 1). For many years, this form of acute lung collapse was the principal method of TB treatment. By decreasing oxygenated air volume, the aims were to impede the spread of the aerobic microorganisms and to reduce mechanical injury to the lung [2]. After the

Prof. Lorenzo Corbetta

University of Florence, Careggi Hospital

Largo Brambilla, 3

IT-50134 Firenze (Italy)

E-Mail lorenzo.corbetta@unifi.it 

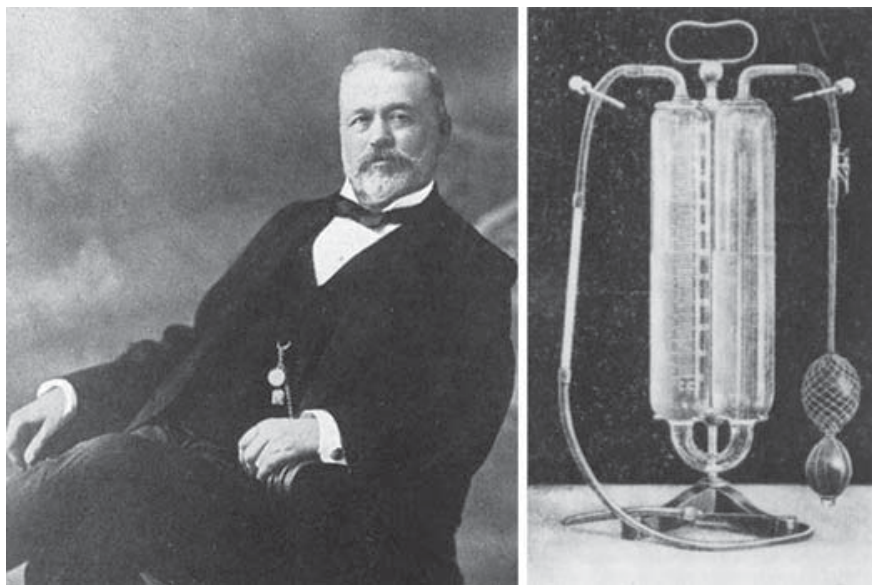

Fig. 1. Dr. Carlo Forlanini (1847-1918) and his apparatus for creating an artificial pneumothorax (1882).

review of his experience in 1882, Carlo Forlanini [3] helped to popularize the procedure. Although no rigorous studies assessing or proving the efficacy of this technique were done, more than 100,000 patients with pulmonary tuberculosis were treated by induced pneumothorax over the next 25 years [4-6].

The discovery of streptomycin in 1943 began a new era of treatment [7], after which new drugs have been added to the therapeutic arsenal, making collapse therapy nonrelevant. However, the combination of modern medical management together with Forlanini's induced pneumothorax has never been fully investigated apart from a 2006 study from Russia, which showed that the use of artificial pneumothorax as adjunctive treatment in patients with multidrug-resistant tuberculosis (MDR-TB) could lead to improved outcomes [8]. Several clinical situations could benefit from non-pharmacological complementary therapies, such as the management of some sequelae and complications of difficult-to-treat TB, MDR-TB and extensively drug-resistant tuberculosis (XDR-TB), all of which have a high risk of complications and death. MDRTB is defined as TB caused by Mycobacterium tuberculosis that is resistant to at least isoniazid and rifampicin, and XDR-TB [9] as resistance to fluoroquinolone and one second-line injectable drug (capreomycin, kanamycin or amikacin). The term XDR-TB was used for the first time in March 2006, in a report jointly published by the US Centers for Disease Control and Prevention (CDC) and the WHO to describe a disease caused by strains of $M$. tuberculosis that were resistant not only to isoniazid and rifampicin (i.e. MDR-TB) but also to at least 3 of the 6 classes of second-line anti-TB drugs (aminoglycosides, polypeptides, fluoroquinolones, thioamides, cycloserine and para-aminosalicylic acid) $[10,11]$.

Totally drug-resistant tuberculosis has been described in Iran, India and South Africa [12-15]. Despite the advent of bedaquiline, failures to treatment are already emerging, such as a recent case report of a patient who developed resistance to both bedaquiline and delamanid (NEJM) [16]. Thus, there is a growing population of programmatically incurable TB that is expanding in countries such as South Africa, Russia, India and China [17, 18]. The WHO 2015 global tuberculosis report estimates that 9 million new cases of tuberculosis occurred in 2013, an increase from the 8.6 million cases estimated for 2012 [19]. According to the WHO, an estimated 480,000 new cases of MDR-TB occurred in 2013, making up 3-5\% of the estimated 9 million people who developed tuberculosis that year. The MDR and XDR forms of tuberculosis greatly complicate patient management, particularly in resource-poor, national tuberculosis programs. MDR-TB treatment success rates, defined as clinical and microbiological responses, are between 44 and 60\% [20].

The poor treatment outcomes of MDR and XDR tuberculosis highlight the urgent need for the development of new antituberculous drugs, treatment regimens and other adjunct treatment approaches to improve outcomes. The treatment time for MDR-TB is longer and more difficult than for a typical case of TB. According to WHO guidelines, the recommended duration of treatment is at least 20 months for most patients, which may be modified according to the patient's response to therapy. Previously treated MDR and XDR patients should receive at least 24 months of treatment [9]. Among the therapeutic options are second-line drugs, which, unfortunately, are expensive and associated with many side effects. A complete course of therapy for a patient with MDR-TB could cost as much as 15,000 USD for drugs and as much as 483,000 USD for hospitalization. The low cure rate for MDR-TB is similar to that reported for TB treatment prior to the availability of effective anti-TB drugs [21].

Because present TB medical therapy generally proves to be inadequate for curing MDR-TB, adjunctive pulmonary resection has been advocated in selected patients with localized disease such as a cavitary lesion or a single destroyed lobe. In these cases, the management of cavities consists of the combination of anti-TB chemotherapy and adjuvant lung resection [22-30].

The most likely mechanism by which surgery is beneficial is a decrease in the bacillary burden through the 
Fig. 2. Zephyr EBV.

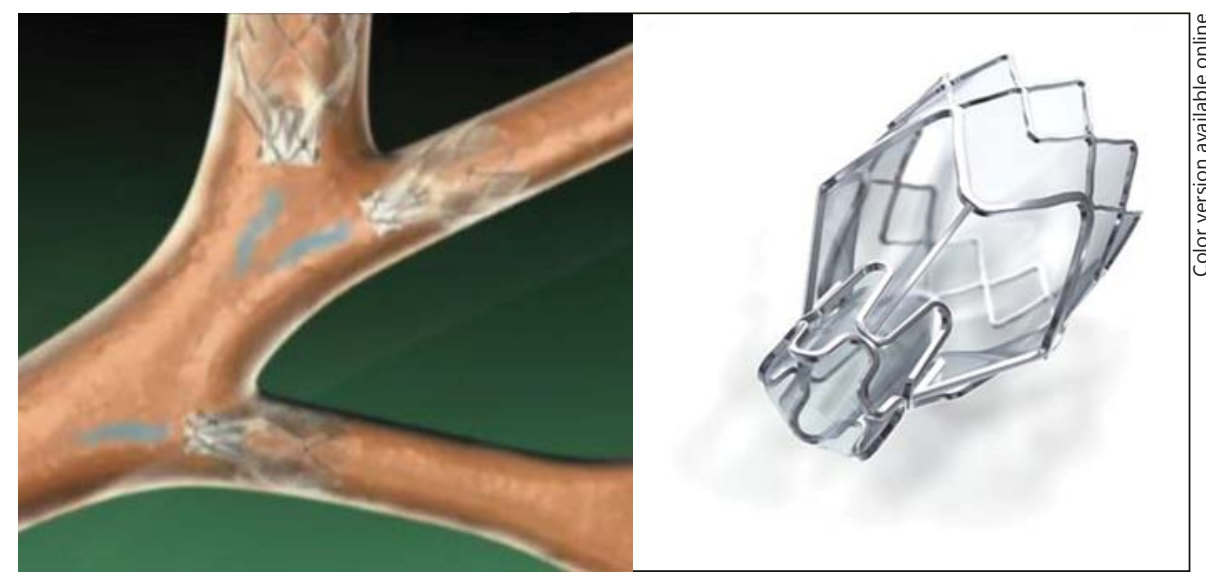

removal of a large area of abnormal lung parenchyma and poorly drug-penetrating granulomatous cavities. Thickwalled cavitary lesions and areas of destroyed lung contain up to $10^{7}-10^{9} \mathrm{M}$. tuberculosis organisms even in patients who are sputum culture negative. These tubercular lesions are penetrated poorly by antituberculous drugs. Cavities act not only as huge reservoirs of $M$. tuberculosis infection but also as the probable site of the development of drug resistance. The surgical removal of cavities could enhance the sterilizing properties of postsurgical chemotherapy and increase the likelihood of treatment success in these selected patients [24, 31, 32]. Kempker et al. [33] demonstrated that the tuberculous cavity promotes the emergence of increasingly drug-resistant bacilli populations during treatment in $M$. tuberculosis isolates from resected cavities among patients with MDR and XDR-TB.

In patients who already have high drug resistance and limited treatment options, the development of further drug resistance could have unfavourable clinical consequences. A recent systematic review and meta-analysis of 24 comparison studies of MDR- and XDR-TB (involving more than 5,000 patients) found a significant association between surgical intervention and successful outcome when compared to non-surgical treatment alone (OR 2.24, 95\% CI: 1.68-2.97) [34]. Subgroup analyses of studies involving XDR-TB patients revealed an even more pronounced treatment effect (OR 4.55, 95\% CI: 1.32 15.7). However, surgery frequently involves postsurgical complications. In addition, not all patients are suitable candidates. With careful patient selection, the operative mortality in lung resection is less than 5\% [35-40]. Common complications range in a frequency between 12 and $30 \%$ and include bleeding, empyema, wound complications and bronchopleural fistula.
There is thus a pressing need for new drugs and additional interventions to improve these outcomes, particularly in XDR-TB.

We hypothesized that a recent form of endobronchial lobar collapse therapy - the insertion of Zephyr ${ }^{\circledR}$ (Pulmonx Inc., Redwood City, Calif., USA) one-way endobronchial valves (EBVs) - may be an effective complementary treatment in the management of MDR-TB, XDR$\mathrm{TB}$ and other forms of cavitary and difficult-to-treat TB and Mycobacteriosis. Because these EBVs are usually indicated to induce atelectasis in chronic obstructive pulmonary disease (COPD) patients with hyperinflated lungs and severe emphysema [41-43], we hypothesized that the use of Zephyr EBVs (fig. 2) could also induce closure of the cavity by collapsing the involved lobe, resulting in desirable effects such as a mechanical anaerobic environment unfavorable to the survival of $M$. tuberculosis, a reduction in the movement of the pulmonary parenchyma to promote a favorable effect on tissue repair, and possibly an enhanced systemic pharmacological drug effect by promoting drug penetration into a smaller affected area.

In a case report published in the International Journal of Tuberculosis and Lung Disease [44], we showed that Zephyr EBV placements in a patient's lung brought a reduction in the cavity size in each of the treated lobes and a negative sputum smear and culture within 5 months after valve placement. No EBV-related complications occurred, and the patient, having improved, was discharged from the hospital. On the basis of this positive experience, we extended the study to a larger number of patients, not only with MDR tuberculosis but also with difficult-totreat TB from other causes such as recurring atypical mycobacteriosis and drug reaction with eosinophilia and systemic symptoms (DRESS) syndrome. 
Table 1. Procedures and outcomes of the 5 patients treated with Zephyr valves

\begin{tabular}{|c|c|c|c|c|c|c|c|c|c|c|}
\hline Patient & Sex & Indication & $\begin{array}{l}\text { Age, } \\
\text { years }\end{array}$ & $\begin{array}{l}\text { Cavity } \\
\text { location }\end{array}$ & $\begin{array}{l}\text { Date of } \\
\text { implant }\end{array}$ & $\begin{array}{l}\text { Lobar } \\
\text { atelectasis }\end{array}$ & $\begin{array}{l}\text { Closure } \\
\text { of cavity }\end{array}$ & $\begin{array}{l}\text { Time to } \\
\text { sputum } \\
\text { negative }\end{array}$ & $\begin{array}{l}\text { Latest } \\
\text { sputum } \\
\text { test }\end{array}$ & Valve removal (date) \\
\hline \multirow[t]{2}{*}{1} & \multirow[t]{2}{*}{$\mathrm{F}$} & \multirow[t]{2}{*}{ XDR-TB } & \multirow[t]{2}{*}{29} & 1. RML & May 19, 2011 & no & yes & 5 months & negative & yes (October 11, 2012) \\
\hline & & & & $\begin{array}{l}\text { 2. posterior } \\
\text { segment } \\
\text { of LUL }\end{array}$ & January 11, 2012 & no & yes & & & yes (November 7, 2012) \\
\hline 2 & $\mathrm{M}$ & M. xenopi & 65 & LUL & June 8, 2012 & $\begin{array}{l}\text { target lobe } \\
\text { volume reduction }\end{array}$ & yes & n.a. & negative & no \\
\hline 3 & $\mathrm{M}$ & MDR-TB & 50 & LUL & $\begin{array}{l}\text { November 21, } \\
2013\end{array}$ & $\begin{array}{l}\text { target lobe } \\
\text { volume reduction }\end{array}$ & partial & 4 months & negative & no \\
\hline 4 & $\mathrm{~F}$ & Difficult-to-treat TB & 54 & LUL & April 30, 2014 & yes & yes & 2 months & negative & yes (March 12, 2015) \\
\hline 5 & $\mathrm{~F}$ & TB/DRESS & 59 & LUL & October 22,2014 & yes & yes & n.a. & n.a. & yes (January 30, 2015) \\
\hline
\end{tabular}

All decisions regarding the treatment (including surgery or valves) were made by a multidisciplinary team of specialists and were approved by the Hospital for the offlabel use of Zephyr valves. The current report describes the authors' experience with lobar collapse therapy by Zephyr unidirectional EBVs as an adjuvant treatment of MDR-TB, XDR-TB and other difficult-to-treat TB patients in order to evaluate the feasibility, effectiveness and safety of this new treatment approach.

\section{Materials and Methods}

The patients included in the study were treated for TB symptoms at the Infectious Disease Units of the Careggi Hospital, Florence, and the Angelo Hospital, Venice, between 2010 and 2015. Five patients (mean age $52.6 \pm 9.7$ years, range $31-69,60 \%$ female) were enrolled. All had severe lung destruction with one or more cavities, were ineligible for surgical resection and had slow or unsatisfactory responses to standard drug treatments (table 1).

The exclusion criteria were either severe respiratory or cardiac failure that would prevent bronchoscopy and sedation, or a patient's refusal to participate in the study. At the time of diagnosis, all TB patients had sputum specimens submitted for M. tuberculosis culture, identification and drug susceptibility testing to firstline drugs (isoniazid, rifampicin, streptomycin and pyrazinamide). For all patients with MDR-TB, sputum smear and culture tests were repeated weekly throughout treatment. All MDR-TB isolates were tested further for resistance to second-line drugs, including kanamycin, capreomycin, ofloxacin, protionamide, cycloserine, pamino salicylic acid and thioacetazone.

The EBVs used were one-way Zephyr valves, CE marked and approved for use by both hospitals. These devices have been used successfully in the treatment of pulmonary emphysema. The valves are positioned through a flexible bronchoscope equipped with a minimal operating-channel diameter of $2.8 \mathrm{~mm}$ that allows for insertion of the delivery catheter for the specific placement of the valve. One patient required intubation with a rigid bronchoscope into which a flexible bronchoscope was inserted. The Zephyr valve is designed to prevent the inflow of inhaled air reaching the segment or target lobe, while allowing the outflow of air and secretions during exhalation. The EBV is contained in a self-expandable nitinol frame that expands and facilitates adhesion and shaping to bronchial walls up to $8.5 \mathrm{~mm}$ in diameter. The result of emptying air from lung tissue using valves is analogous to that of lobar removal with surgery. However, the absence of collateral ventilation $(\mathrm{CV})$ is a requirement for obtaining significant lobar volume reduction with valves. In these patients, CV was assessed by analysis of fissure integrity from high-resolution CT scans. Depending on the patient, lobar atelectasis can be achieved by placing one or more valves in the lobar branches or segmental bronchus to be treated. One patient (Patient 1) was treated with a lobar approach in the middle lobe (ML) and consequently with a segmental approach in the apicoposterior branch of the left upper lobe (LUL). The procedures were performed under spontaneous breathing and conscious sedation using 2-5 mg midazolam, with the exception of 1 patient intubated with a rigid bronchoscope who required mechanical ventilation and deep sedation with propofol. The 2 patients with MDR/XDR-TB were treated under negative pressure and six air changes per hour inside an isolation room in the Infectious Disease Department of the Careggi University Hospital (Patients 1 and 3). The 3 patients with difficult-to-treat TB were treated in the bronchoscopy suite of the Careggi University Hospital. The operators wore personal protection and N99 masks. Mechanical respirators were not used.

The Careggi University Hospital's Ethics Committee approved the study. All patients signed an informed consent regarding the use of data and the possible risks associated with the procedure.

Chest X-rays were taken before the procedure, $1 \mathrm{~h}$ after implantation and 7 days later. Thorax CT scans were taken before the procedure, 30 days later and again 4-10 months after implantation. In cases where valve removal was indicated, a chest CT scan was taken 1 month later to evaluate the outcome. Direct sputum tests and sputum cultures were performed before and immediately after implantation, 7 days later and every 7 days thereafter until the direct sputum test became negative.

Oxygen saturation was measured daily on all patients, and blood gas analysis was measured when needed. 

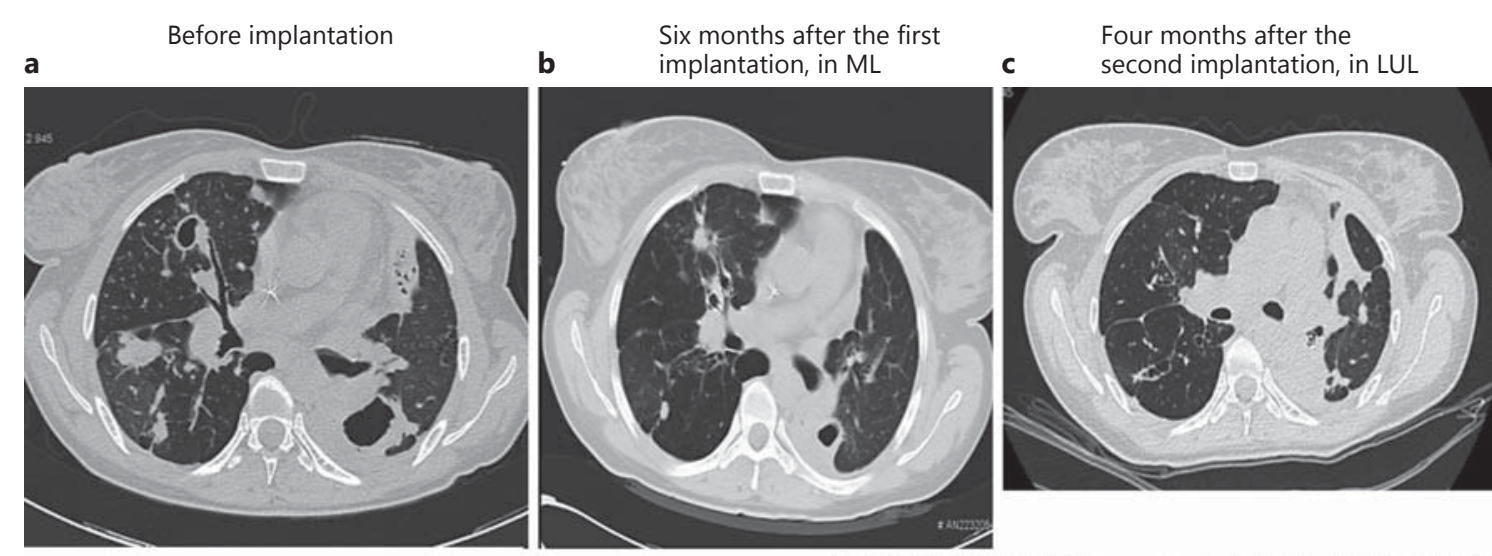

Fig. 3. Patient 1: CT scans before (a) and after (b) the first valve implantation, and after the second valve implantation (c).
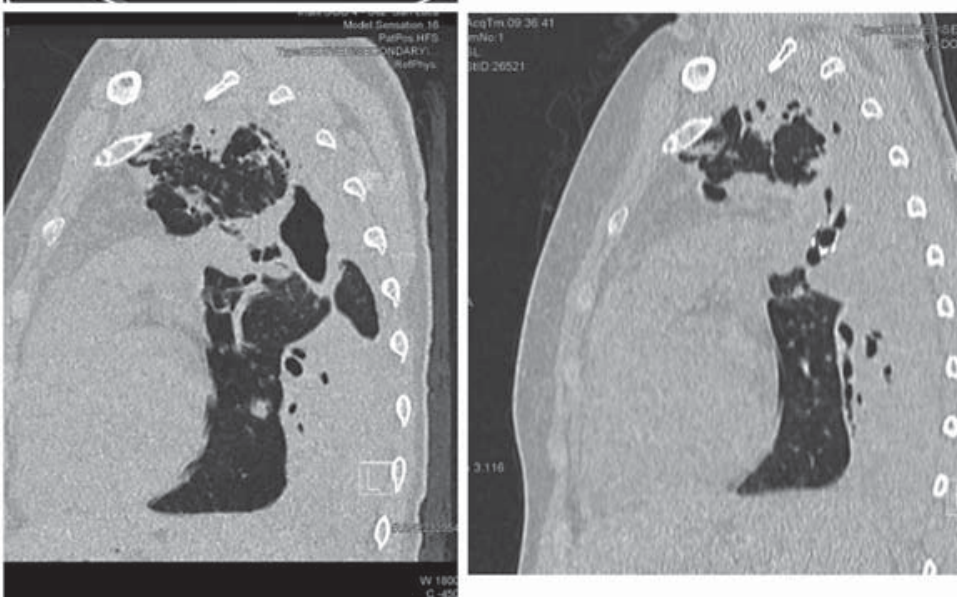

\section{Results}

We report here our early experience with 5 patients (mean age: $52.6 \pm 9.7$ years, $60 \%$ female) with cavities: 4 TB patients (1 MDR, 1 DRESS and 1 difficult-to-treat with extensive disease) and 1 with relapse of atypical mycobacteriosis. TB cavity collapses were attempted using Zephyr valves, while maintaining optimal anti-TB chemotherapy treatment. The cavities were located in the LUL (3), right upper lobe [RUL (1)] and right ML [RML + LUL (1)], and thus were also the targets of EBV placements. In each patient, 2 or 3 valves were required to isolate a cavity. Four patients were sputum positive at the time of the procedure.

The insertions of the Zephyr valves were achieved without complications. Complete cavity collapses were observed on CT scans in 4 of the 5 patients. The partial cavity collapse in the one patient probably resulted from an absence of atelectasis caused by the presence of interlobar CV due to lack of integrity of lobar fissures, or from a possible partial lobar occlusion.
All patients improved in clinical status after treatment. Sputum became negative after an average of 3.6 months (range: $2-5$ ) and remained negative to the end of followup (mean follow-up: $23 \pm 12$ months, range 6-40). There were no severe short or long-term complications related to this form of treatment, apart from 1 patient with a pneumothorax not requiring drainage.

In our series, we removed the valves in 3 of the 5 patients after 4,8 and 10 months, respectively, without interrupting the process neither of cavity closure nor the improvement of the TB. Furthermore, we witnessed a reexpansion of the lobes. The cases are described below, summarized in table 1 and illustrated in figures 3 and 4 .

\section{Patient 1}

Patient 1 is a 29-year-old female admitted to our clinic for the treatment of XDR-TB in January 2011. She was previously diagnosed with TB in her home country Romania in 2001, received first-line drug treatment but relapsed in 2006 and 2009. In 2011, as determined by the drug susceptibility test, the patient was considered affect- 
a
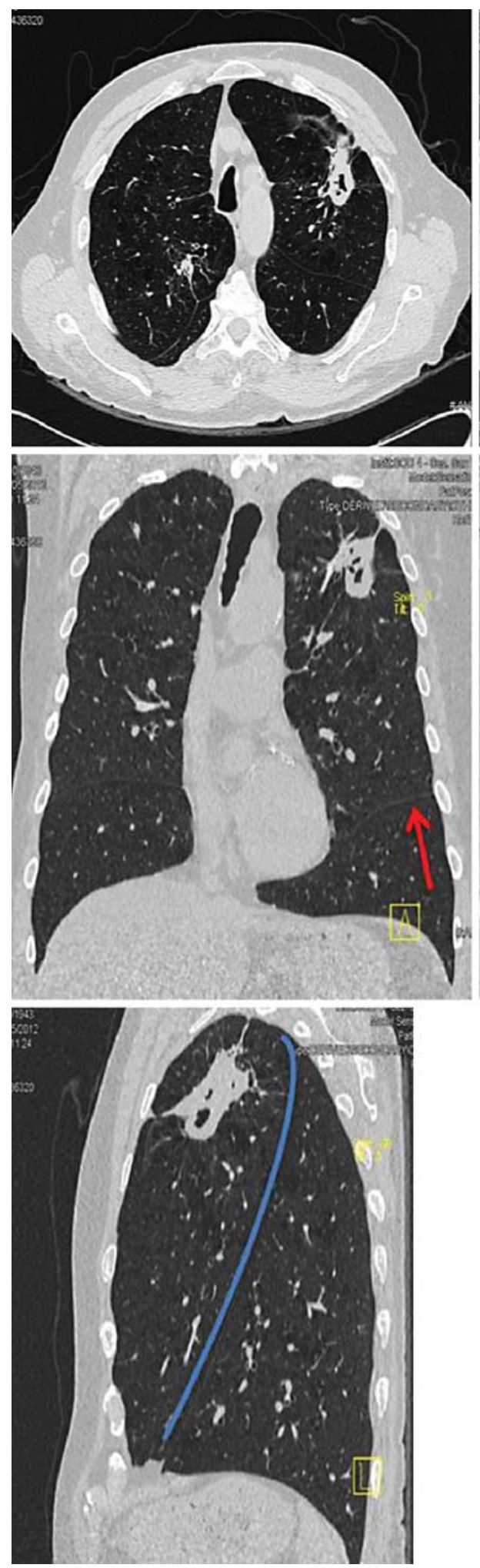
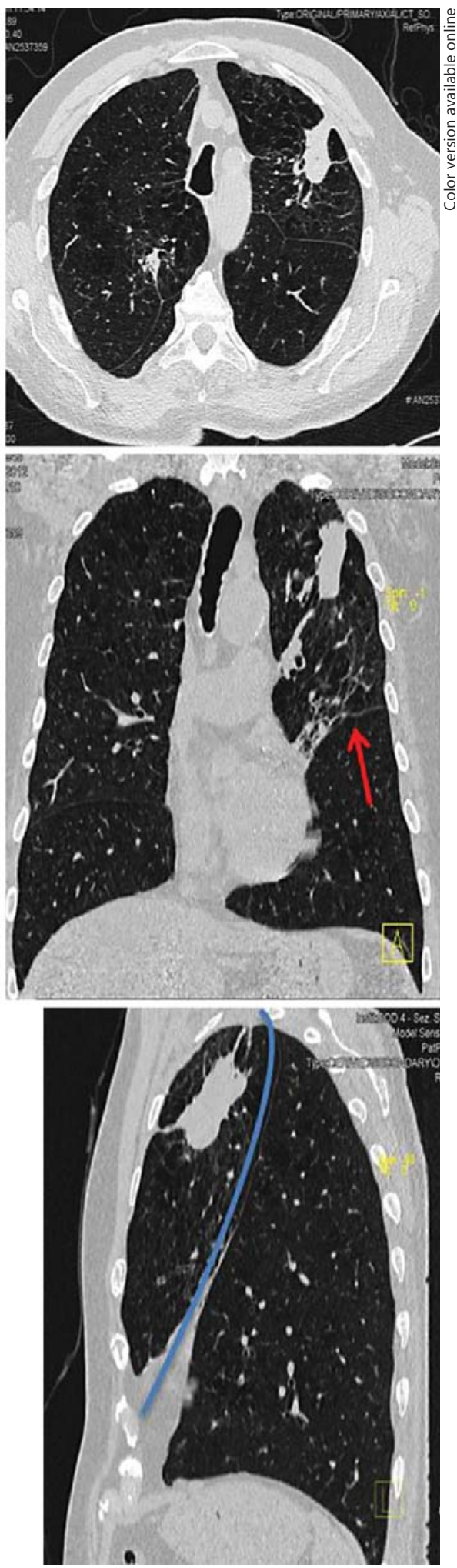

Fig. 4. Patient 2: CT scans before (a) and 3 months after (b) implantation. Red arrows and blue lines indicate the interlobar left fissure (colors refer to the online version only).
Respiration 2016;92:316-328

Lobar Collapse Therapy with EBVs to Treat Drug-Resistant TB 
ed by XDR-TB and ineligible for surgery given the extent of her disease. Her sputum culture recorded a heavy growth of M. tuberculosis. A CT scan (January 26, 2011) showed multiple cavities in the LUL, RML and right lower lobe (RLL). A drug susceptibility test demonstrated that the isolate was resistant to first- and second-line antibacterial agents and was only susceptible to amikacin and linezolid. Our treatment plan was initiated in January 2011 with (i.v.) imipenem/cilastatin, amikacin, linezolid and (p.o.) clofazimine. The patient showed no improvement in asthenia, persistent cough, intermittent fever and episodes of hemoptysis. Repeated evaluation by sputum analysis (every 10-15 days) and CT (March 2011) failed to show improvement. Given the patient's deteriorating condition, we considered EBV placement. Following a pretreatment CT scan, the decision was made to target the RML, where we could treat a cavity and an entire lobe without significantly affecting ventilation. The CT analysis showed the integrity of the fissures. If successful, the aim was to continue treating her other lobes. The implantation in RML was performed on May 19, 2011. Using local anaesthesia and conscious sedation, two 4-mm Zephyr valves were inserted into the lateral and medial segmental bronchi of the ML bronchus. On May 27, 2011, terizidone was added to the treatment regimen. No hypersecretion was observed during the bronchoscopy. At the 1-month follow-up, the CT scan showed a marked reduction in the size of the ML cavity. However, the sputum culture remained positive. TMC207 bedaquiline (experimental drug) was started in October 2011. After 1 month, the sputum smear and culture turned negative. The CT scan of November 2011 showed a complete closure of the RML cavity. It was then decided to remove the RML EBVs and to implant other valves to target a persistent cavity in the LUL. On January 11, 2012, in a single procedure, the two EBVs were removed from the ML, and a 5.5- $\mathrm{mm}$ Zephyr valve was placed in the apicoposterior branch of the LUL. This segmental approach was undertaken as a balance between the goal of closing the cavity and the poor functional condition of the patient that prevented exclusion of the entire lobe. The 1-month followup CT scan showed a volume reduction of the segment and a reduction in the size of the cavity (fig. 3 ). The patient became asymptomatic. At the 10-month follow-up (October 2012), the CT scan demonstrated a further reduction of the cavity in the LUL and a stabilization of the ML. All EBVs were subsequently removed on November 7, 2012. At the 3-year follow-up (2015), the CT scan demonstrated a partial reventilation of the LUL and a stabilization of the RML.

\section{Patient 2}

In 2009, a 65-year-old, HIV-negative male smoker with diagnosed emphysema was diagnosed with atypical mycobacteriosis and underwent a segmental resection of the RUL for suspected malignancy. The histology revealed an atypical mycobacteriosis caused by M. xenopi; he was treated for 9 months with clarithromycin, rifampin and ethambutol. In May 2011, he had a relapse of infiltration with a new cavity in the LUL. The sputum culture recorded a heavy growth of M. xenopi. The patient refused to repeat antibacterial treatment. The CT scan revealed that the LUL was affected by a large cavity with thickened walls communicating with the bronchial tree. The CT analysis showed the integrity of the fissures. On June 6, 2012, under local anesthesia, three Zephyr valves were inserted into the segmental bronchi of the LUL by flexible bronchoscope. No hypersecretion was observed. The chest CT scan taken 1 month later showed that the cavity in the LUL had decreased in size. Although no complete lobar atelectasis was achieved, there was a significant reduction in the lobar volume (fig. 4). The patient developed a pneumothorax not requiring drainage and rapidly recovered. There was a slight improvement in the results of the functional tests. Before implantation, the values were as follows: $\mathrm{FEV}_{1} 2.77 \mathrm{~L}$ (77\%), $\mathrm{FEV}_{1} / \mathrm{FVC}$ 62\%, RV 3.78 L (143\%), TLC 8.31 L, DLCO 66\%. After implantation, the following values were measured: $\mathrm{FEV}_{1}$ 2.97 L (85\%), FVC 4.95 L (108\%), FEV 1 /FVC 60\%, RV 2.65 L (97\%), TLC 7.76 L, DLCO 72\%. The 1-year followup demonstrated continuing closure of the treated lesion. As the patient suffered from emphysema and derived clinical benefit from the treatment, it was decided not to remove the valves. To date, the patient has remained asymptomatic.

\section{Patient 3}

In November 2013, a 50-year-old, HIV-negative male smoker diagnosed with MDR-TB had been treated with optimal chemotherapy from October 2013. However, the sputum culture recorded persistent heavy growth of MDR-TB in spite of the pharmacological treatment in the hospital with linezolid, levofloxacin, protionamide and cycloserin. The CT scan showed that the LUL was affected by a persistent, large cavity; the patient had $38^{\circ} \mathrm{C}$ fever and severe respiratory failure (room $\mathrm{PaO}_{2}: 44 \mathrm{~mm} \mathrm{Hg}$; fig. 5). On the basis of the CT scan and the deterioration of respiratory conditions, it was decided to insert valves to collapse the LUL. The CT analysis of the fissures was not conclusive for the severe lung destruction. The operation took place on November 21, 2013. Three Zephyr 


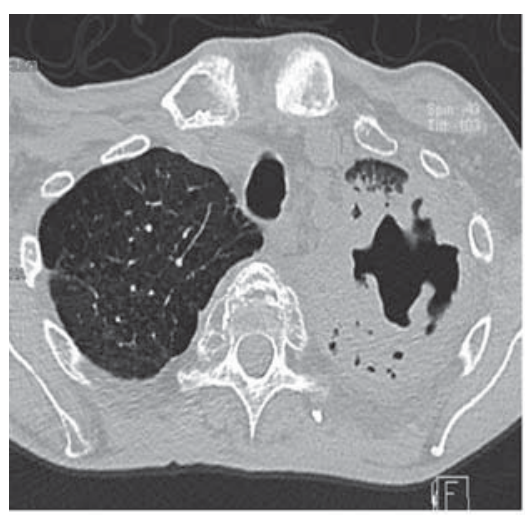

November 2013, before treatment

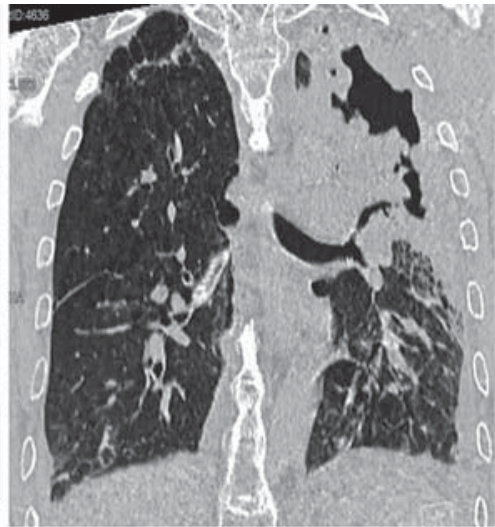

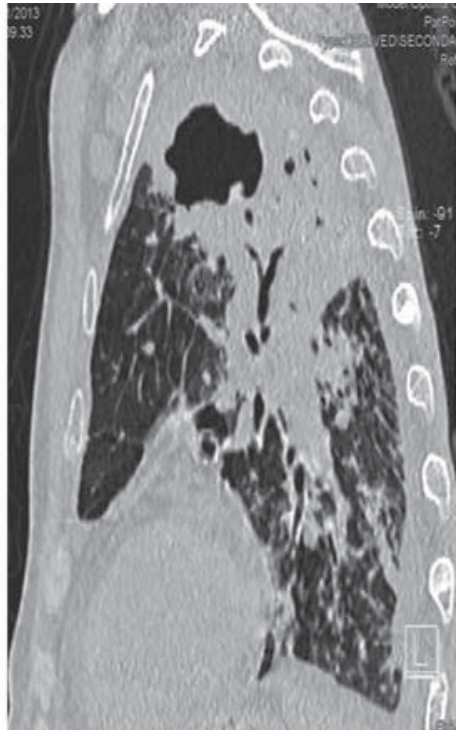

b

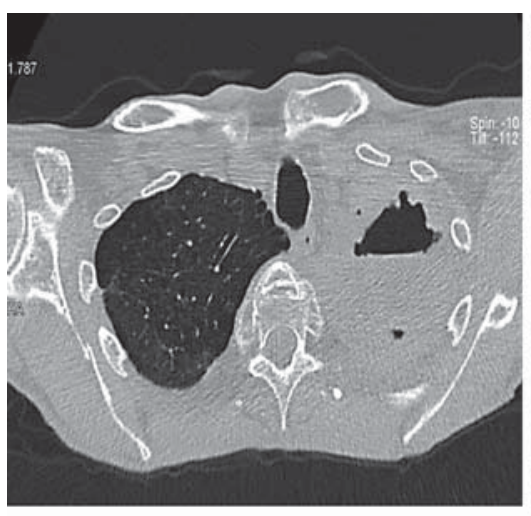

December 2013, after treatment

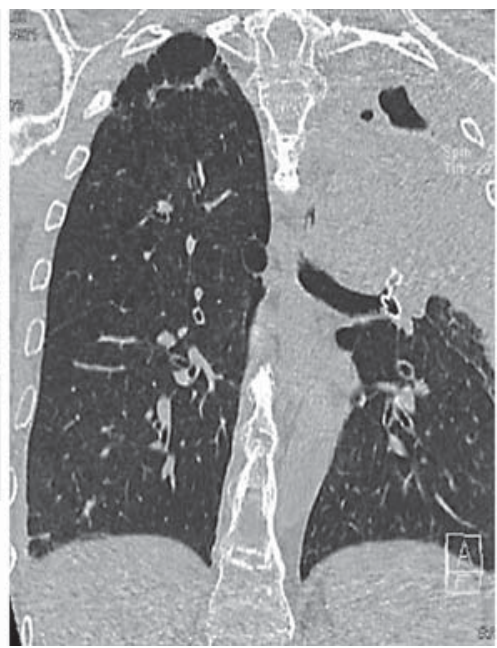

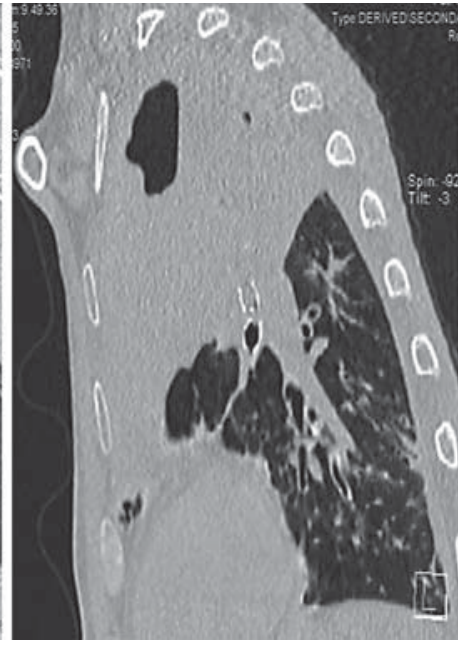

Fig. 5. Patient 3: CT scans before (a) and 1 month after (b) valve implantation.

valves were inserted into the segmental bronchi of the LUL. The chest CT scan 3 weeks after the procedure showed only a partial atelectasis and partial closure of the cavity. The patient continued to smoke and required repeat bronchoscopies to aspirate secretions. Despite achieving only a partial collapse, we decided not to remove the valves due to the significant clinical improvements in arterial blood gas analysis (ABG) and the dyspnea we observed immediately after implantation and in the months following the operation (room $\mathrm{PaO}_{2}$; before treatment: $53 \mathrm{~mm} \mathrm{Hg} ; 2$ weeks after treatment: $94 \mathrm{~mm}$ $\mathrm{Hg})$. Sputum smears became negative within 4 months. The patient interrupted the pharmacological treatment in October 2015 and is clinically stable.

\section{Patient 4}

In January 2014, a 53-year-old, HIV-negative female diagnosed with TB was treated with chemotherapy, but 

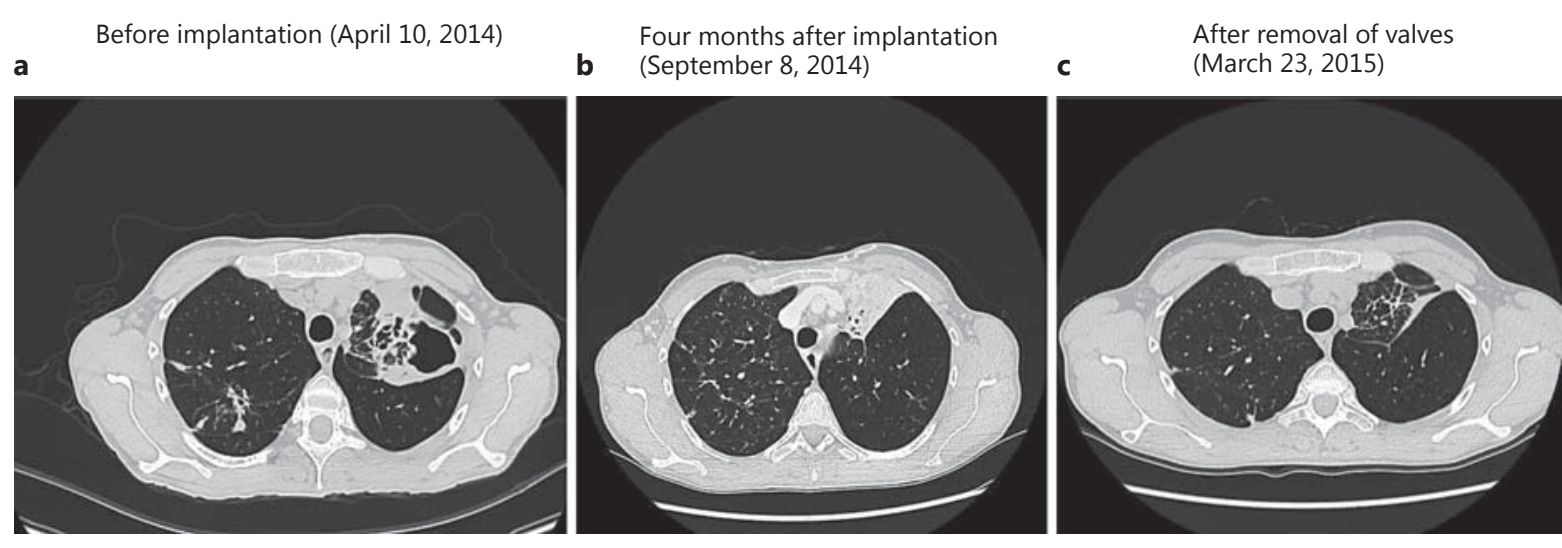

Fig. 6. Patient 4: CT scans before (a) and after (b) valve implantation, and after valve removal (c).

after 5 months of therapy, sputum culture remained positive with a heavy growth of MDR-TB. The CT scan showed a persistent large cavity in the LUL (fig. 6a). The $\mathrm{CT}$ analysis showed the integrity of the fissures. There were no improvements in asthenia, persistent cough, intermittent fever and episodes of hemoptysis. On the basis of the CT scan, we decided to insert 3 valves in the segmental bronchi of the LUL (fig. 6b). The procedure took place on 30 April 2014, and the sputum smear turned negative within the following 2 months. We observed no hypersecretion during the bronchoscopy. Chest CT scans at 1 and 4 months after implantation showed complete lobar atelectasis and closure of the cavity (fig. 6b). During the months after treatment, there was an improvement in clinical symptoms, and the patient returned to active life (work) within 2 months. The EBVs were removed 10.5 months later. The CT scan taken 3 weeks after removal showed a stable closure of the cavity and a welcome partial reventilation of the LUL after such a long duration of atelectasis (fig. 6c).

\section{Patient 5}

A female, 59 years old, with type 2 diabetes and affected by TB since March 21, 2014, was diagnosed with DRESS syndrome on April 26, 2014, after 1 month of standard treatment, which forced an interruption of the pharmacological treatment. A CT scan at follow-up on September 25, 2014, demonstrated a large RUL pleuroparenchymal cavity (fig. 7a). The CT analysis showed the integrity of the fissures. She was asymptomatic. To resolve the cavity, 3 valves were implanted in the RUL on October 22, 2014. No hypersecretion was observed during the bronchoscopy. On December 12, 2014, the patient was clinically stable, and a chest CT scan showed complete RUL atelectasis with cavity closure (fig. 7b). On February 1,2015 , on the basis of the CT scan, we decided to remove the valves. A chest CT scan on February 25, 2015, demonstrated partial reventilation of the RUL and stable closure of the cavity (fig. $7 \mathrm{c}$ ).

\section{Discussion}

In the present series of 5 patients, Zephyr EBVs were used to induce lobar collapse or lobar volume reduction of the affected lobes of patients with MDR, difficult-totreat TB or Mycobacteriosis concomitantly treated with conventional medical therapy. The result was a reduction in cavity sizes within 1 month after valve implants. In each of the treated lobes, the closure of the cavities remained stable in the 12-56 months observed after implantation and in the 8 months observed after valve removal in the 3 cases in whom valves were removed. Some patients even demonstrated further clinical and ABG improvements. One patient had emphysema; another patient continued smoking and was likely to have COPD according to his clinical history, but no lung function test was available. The principal impact of the treatment was the anatomical decrease of the cavity size resulting from the mechanism of the valves, which is known to induce collapse or at least volume reduction of the treated lobe. In these patients, it resulted in an accelerated TB cavity closure. This is a welcome side effect given that the closure of a TB cavity usually takes a very long time (often years), together with ensuing risks of superinfection and relapses. 

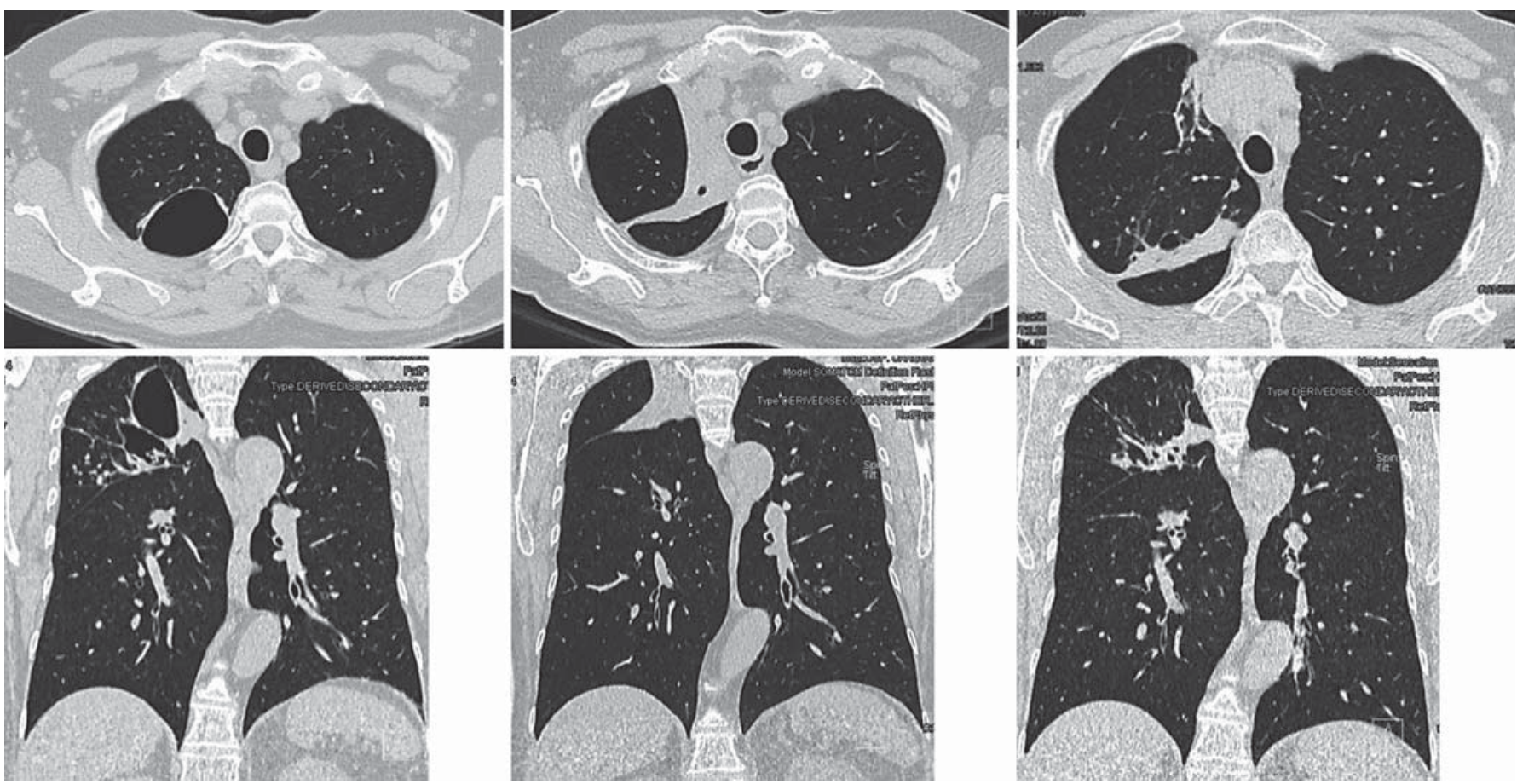

Fig. 7. Patient 5: CT scans before (a) and after (b) valve implantation, and after valve removal (c).

No patient died or experienced severe adverse events related to valve implantation. One patient experienced a mild pneumothorax that resolved without drainage. All patients are currently alive and in a stable medical condition.

The sputum smears and cultures turned negative 3-5 months after EBV placement. These results could be attributed to the combination of pharmacological therapy and the creation of atelectasis, or at least of parenchymal volume reduction and hypoventilation induced by the valves.

The only other reports in the literature regarding the use of a similar approach in the treatment of tuberculosis come from Russia. These authors used Russian-made silicone valves, which reportedly promoted stabilization and regression of the tubercular process. The valves were implanted in 89 patients with MDR-TB and in 118 patients with infiltrative pulmonary TB. The Russian silicone valve was fitted outside of a 6-mm bronchoscope and pushed in place with the bronchoscope and a forceps in the instrument channel [45-47].

The results of our study indicate that one-way EBV Zephyr valve implantation in TB patients, a much less in- vasive approach than lung reduction surgery, is safe and free of severe complications. There are no major contraindications for this procedure apart from the high risks of severe respiratory or cardiac failure from the bronchoscopy itself. Severe mucostasis seems to be a contraindication for valve therapy, as it seems to be associated with a higher risk of poststenotic pneumonia in the treatment of emphysema. In our series, we had unsatisfactory results plus the need for repeated mucus aspirations in Patient 3 who had chronic bronchitis and continued to smoke.

Adjunctive pulmonary resection has been advocated in selected patients with localized MDR-TB and cavitary lesions or a single destroyed lobe $[3,22-31,33]$. However, not all patients are suitable candidates, and surgery frequently involves postoperative complications. Induced lobar collapse with valves has the advantages of being reversible and of allowing reventilation of the lobe after the cavity has healed, as demonstrated in 3 of our patients.

The successful use of valves for the treatment of hyperinflation in emphysema has been well investigated [41, $48,49]$. A necessary requirement for successful lobar collapse is the integrity of the fissure because the likelihood of successful atelectasis depends upon the absence of CV 
between the target and adjacent lobes. This can be assessed before treatment with a catheter-based system (Chartis System; Pulmonx Corporation, Redwood City, Calif., USA) that measures airflow escaping the target lobe and, therefore, demonstrating the lack of CV [5052]. In our series, we treated all patients with the goal of obtaining atelectasis. Our data suggest that, as with the treatment of emphysema, the inducement of atelectasis is required in order to achieve better results in the treatment of cavities. For this reason, the treatment must be lobar, preferably after exclusion of CV between lobes. Although we did not use Chartis, we assessed CV by fissure integrity analysis from high-resolution CT scans, a method that has comparable accuracy [53].

Nevertheless, for patients with severe DR-TB and severely damaged lungs but intact fissures, this treatment should be approached with extreme caution, and valves should be removed in the case of treatment failure. In 1 patient, a heavy smoker, the treatment achieved partial atelectasis and lesser radiological improvements, a result of smoke-induced hypersecretions that had an impact on the proper functioning of the valves, as was verified with bronchoscopy in this case. Nevertheless, he did show improvements in ABG and dyspnea.

In patients with bilateral cavities, the treatment of 2 bilateral lobes simultaneously increases the risk of bilateral pneumothorax. In our study, there was 1 patient with bilateral cavities. Due to the high risk of pneumothorax following valve therapy, the bilateral valve treatment was performed in 2 subsequent sessions [54].

One additional aspect to consider is control of infection. If this procedure is to be performed on patients with, or more extreme than, XDR-TB, in whom the mortality rate is substantial, the control of infection must be addressed. In our series, the procedure was performed on 2 patients with MDR/XDR-TB under negative pressure, with 6 air changes per hour, in an isolation room in the Infectious Disease Department of the Careggi University Hospital (Patients 1 and 3). In the 3 patients with difficult-to-treat TB but no DR-TB, bronchoscopy was performed in the bronchoscopy suite. The operators must wear personal protection measures and N99 masks.

In our series, we removed the valves in 3 of the 5 patients, after 4, 8 and 10.5 months, respectively, without an impact on either the process of cavity closure or the improvement of the TB. After valve removal, we witnessed a re-expansion of the lobe. Valves were not removed in 2 other patients who experienced continued clinical benefits from the reduction of hyperinflation (the original indication of valve treatment). Both of these patients were heavy smokers, and one had diagnosed COPD and emphysema. At present, we do not know the duration of atelectasis required for the successful treatment of TB; the duration in which the valves must remain in place to completely reverse the cavities remains to be investigated.

The treatment by lobar collapse draws its inspiration from Forlanini's method of lung collapse with artificial pneumothorax. The effects are due to the juxtaposition of the cavity walls; the caseous areas are rendered drier and the diseased surface is, at least, reduced in size. The advantage of lobar collapse with valves is that it targets a lobe, whereas lung collapse does not. This form of lobar collapse is also reversible, unlike that achieved with surgery, thus allowing for lobar re-expansion and renewed gas exchange following valve explantation.

At present, the main indication of lobar collapse with valves in our series is the presence of a localized cavity not responding to pharmaceutical treatment, but in the future, other indications could be considered, such as the effects of toxemia in patients with MDR or severe and destructive TB. Lobar collapse, applicable to all patients with cavities in addition to the MDR indication (infiltrative or cavitary TB), is especially recommended for faradvanced cases, in particular for those manifesting a rapidly fatal course and showing signs of extensive excavations, in order to restore the lung functionality following removal of the valves. Other applications might include Aspergillus infection and the prevention of fungal infection in residual cavities, and as a bridge to surgical intervention in selected cases. Presently, there is no evidence supporting these indications.

The number of classical cases with indications of progressing, marked or even advanced disease that are suitable for lobar collapse is low. The percentage of suitable cases is likely to increase if we keep in mind that most progressive TB cases at some time in their course must reach a stage when lobar collapse might be used with advantage and that a case unsuitable today might have been suitable yesterday, or may become so tomorrow. Although our experience is of a region of the world with low rates of MDR-TB and difficult-to-treat TB, this procedure could be of greater value and use in regions with higher incidences of MDR-TB or difficult-to-treat TB, or in other settings such as low compliance, intolerance of or contraindications to a drug regimen, respiratory failure, etc. The TB recurrence rate with drug treatment is low in the western world but elevated elsewhere.

The general costs of MDR-TB are high, ranging from 9,235 USD in low-income countries to 48,553 USD per patient treated in upper middle-income countries. Exam- 
ple costs per case for MDR-TB treatment are South Africa (USD 6,772), Russia (USD 14,600) and Peru (USD 2,400) [55-57]. In South Africa, the per-patient cost of XDR-TB is USD 26,392, 4 times greater than that of MDR-TB and 103 times greater than that of drug-sensitive TB (USD 257) [57].

Therefore, the cost of valves and their implantation should be offset by improved outcomes (fewer relapses, lesser contamination) and reduced medication and hospitalization expenses. EBV valve therapy is also cheaper than surgical lobar resection.

\section{Conclusions}

Whilst limited conclusions can be drawn from these 5 cases, the outcomes from valve treatment in our patients are nevertheless highly promising. EBVs may represent a less invasive and safer adjuvant therapy to optimal drug treatment than surgical lung resection and, therefore, could potentially be safely used in a wider population of
TB patients, with the added advantage that the therapy is reversible. EBV treatment could be an important response to the global MDR- and XDR-TB epidemic and the associated economic burden.

Our early clinical experience shows that endobronchial valve treatment is likely to be a useful adjunct to treating therapeutically destitute patients. More data are required to confirm these hypotheses.

These early results need to be confirmed in a larger patient cohort with a comparative control group and a longer period of follow-up. The improvements in functional status, microbiological load and the optimal time for valve removal after repeated sputum-negative tests, if needed, are questions that remain to be investigated.

\section{Acknowledgements}

Dr. Pierre Grandjean contributed to and reviewed the drafts, and we thank IB Editorial Services LLC for editorial support and Dr. Irene Bellesi for revision.

\section{References}

1 Sakula A: Carlo Forlanini, inventor of artificial pneumothorax for treatment of pulmonary tuberculosis. Thorax 1983;38:326-332.

2 Clive R: The Pneumothorax Treatment of Pulmonary Tuberculosis. London and Aylesbury, Hazell, Watson and Viney, 1917.

3 Forlanini CA: Contribuzione della terapia chirurgica della tisi; ablazione del polmone? Pneumatorace artificiale? Gazz Osp Clin 1882;3:537-705.

4 Kempker RR, Vashakidze S, Solomonia N, Dzidzikashvili N, Blumberg HM: Surgical treatment of drug-resistant tuberculosis. Lancet Infect Dis 2012;12:157-166

5 Daniel T: Collapse and mutilation; in Captain of Death: The Story of Tuberculosis. Rochester, University of Rochester Press, 1997, pp 195-202.

6 Meade R: A history of Thoracic Surgery. Springfield, CC Thomas, 1961

7 Naef AP: The 1900 tuberculosis epidemicstarting point of modern thoracic surgery. Ann Thorac Surg 1993;55:1375-1378.

8 Motus IY, Skorniakov SN, Sokolov VA, Egorov EA, Kildyusheva EI, Savel'ev AV, Zaletaeva GE: Reviving an old idea: can artificial pneumothorax play a role in the modern management of tuberculosis? Int J Tuberc Lung Dis 2006;10:571-577.
9 Zumla A, Chakaya J, Centis R, D’Ambrosio L, Mwaba P, Bates M, Kapata N, Nyirenda T, Chanda D, Mfinanga S, Hoelscher M, Maeurer M, Migliori G: Tuberculosis treatment and management-an update on treatment regimens, trials, new drugs, and adjunct therapies. Lancet Respir Med 2015;3:220-234.

10 Centers for Disease Control and Prevention (CDC): Emergence of Mycobacterium tuberculosis with extensive resistance to secondline drugs - worldwide, 2000-2004. MMWR Morb Mortal Wkly Rep 2006;55:301-305.

11 Migliori GB, Besozzi G, Girardi E, Kliiman K, Lange C, Toungoussova OS, Ferrara G, Cirillo DM, Gori A, Matteelli A, Spanevello A, Codecasa LR, Raviglione MC; SMIRA/TBNET Study Group: Clinical and operational value of the extensively drug-resistant tuberculosis definition. Eur Respir J 2007;30:623-626.

12 Dheda K, Gumbo T, Gandhi NR, Murray M, Theron G, Udwadia Z, Migliori GB, Warren R: Global control of tuberculosis: from extensively drug-resistant to untreatable tuberculosis. Lancet Respir Med 2014;2:321-338.

13 Klopper M, Warren RM, Hayes C, Gey van Pittius NC, Streicher EM, Müller B, Sirgel FA, Chabula-Nxiweni M, Hoosain E, Coetzee G, David van Helden P, Victor TC, Trollip AP: Emergence and spread of extensively and totally drug-resistant tuberculosis, South Africa. Emerg Infect Dis 2013;19:449-455.
14 Udwadia ZF, Amale RA, Ajbani KK, Rodrigues C: Totally drug-resistant tuberculosis in India. Clin Infect Dis 2012;54:579-581.

15 Velayati AA, Masjedi MR, Farnia P, Tabarsi P, Ghanavi J, Ziazarifi AH, Hoffner SE: Emergence of new forms of totally drug-resistant tuberculosis bacilli: super extensively drugresistant tuberculosis or totally drug-resistant strains in Iran. Chest 2009;136:420-425.

16 Bloemberg GV, Keller PM, Stucki D, Trauner A, Borrell S, Latshang T, Coscolla M, Rothe T, Hömke R, Ritter C, Feldmann J, Schulthess B, Gagneux S, Böttger EC: Acquired resistance to bedaquiline and delamanid in therapy for tuberculosis. N Engl J Med 2015;373:19861988.

17 Dheda, Keertan, Barry CE, Maartens G: Tuberculosis. Lancet 2015;387:1211-1216.

18 Dheda K, Migliori GB: The global rise of extensively drug-resistant tuberculosis: is the time to bring back sanatoria now overdue? Lancet 2012;379:773-775.

19 World Health Organization: Global tuberculosis report 2015. http://www.who.int/tb/ publications/global_report/en/.

20 Kim HR, Hwang SS, Kim HJ, Lee SM, Yoo CG, Kim YW, Han SK, Shim YS, Yim JJ: Impact of extensive drug resistance on treatment outcomes in non-HIV-infected patients with multidrug-resistant tuberculosis. Clin Infect Dis 2007;45:1290-1295.
Lobar Collapse Therapy with EBVs to

Treat Drug-Resistant TB 
21 Herzog H: History of tuberculosis. Respiration 1998;65:5-15.

22 Chiang CY, Yu MC, Bai KJ, Suo J, Lin TP, Lee YC: Pulmonary resection in the treatment of patients with pulmonary multidrug-resistant tuberculosis in Taiwan. Int J Tuberc Lung Dis 2001;5:272-277.

23 Iseman MD, Madsen L, Goble M, Pomerantz M: Surgical intervention in the treatment of pulmonary disease caused by drug-resistant Mycobacterium tuberculosis. Am Rev Respir Dis 1990;141:623-625.

24 Lalloo UG, Naidoo R, Ambaram A: Recent advances in the medical and surgical treatment of multi-drug resistant tuberculosis. Curr Opin Pulm Med 2006;12:179-185.

25 Madansein R, Parida S, Padayatchi N, Singh N, Master I, Naidu K, Zumla A, Maeurer M: Surgical treatment of complications of pulmonary tuberculosis, including drug-resistant tuberculosis. Int J Infect Dis 2015;32:6167.

26 Dravniece G, Cain KP, Holtz TH, Riekstina V, Leimane V, Zaleskis R: Adjunctive resectional lung surgery for extensively drug-resistant tuberculosis. Eur Respir J 2009;34:180-183.

$27 \mathrm{Xu} \mathrm{HB}$, Jiang RH, Li L: Pulmonary resection for patients with multidrug-resistant tuberculosis: systematic review and metaanalysis. J Antimicrob Chemother 2011;66:1687-1695.

28 Pontali E, Matteelli A, D'Ambrosio L, Centis R, Migliori GB: Rediscovering high technology from the past: thoracic surgery is back on track for multidrug-resistant tuberculosis. Expert Rev Anti Infect Ther 2012;10:11091115.

29 Freixinet JG, Rivas JJ, Rodríguez De Castro F, Caminero JA, Rodriguez P, Serra M, de la Torre M, Santana N, Canalis E: Role of surgery in pulmonary tuberculosis. Med Sci Monit 2002;8:CR782-CR786.

30 Jouveshomme S, Dautzenberg B, Bakdach H, Derenne JP: Preliminary results of collapse therapy with plombage for pulmonary disease caused by multidrug-resistant mycobacteria. Am J Respir Crit Care Med 1998;157:16091615.

31 Calligaro GL, Moodley L, Symons G, Dheda $\mathrm{K}$ : The medical and surgical treatment of drug-resistant tuberculosis. J Thorac Dis 2014;6:186-195.

32 Canetti G: Present aspects of bacterial resistance in tuberculosis. Am Rev Respir Dis 1965;92:687-703.

33 Kempker RR, Rabin AS, Nikolaishvili K, Kalandadze I, Gogishvili S, Blumberg HM, Vashakidze S: Additional drug resistance in Mycobacterium tuberculosis isolates from resected cavities among patients with multidrug-resistant or extensively drug-resistant pulmonary tuberculosis. Clin Infect Dis 2012; 54:e51-e54
34 Marrone MT, Venkataramanan V, Goodman M, Hill AC, Jereb JA, Mase SR: Surgical interventions for drug-resistant tuberculosis: a systematic review and meta-analysis. Int $\mathrm{J} \mathrm{Tu}$ berc Lung Dis 2013;17:6-16.

35 Man MA, Nicolau D: Surgical treatment to increase the success rate of multidrug-resistant tuberculosis. Eur J Cardiothorac Surg 2012; 42:e9-e12.

36 Kang MW, Kim HK, Choi YS, Kim K, Shim YM, Koh WJ, Kim J: Surgical treatment for multidrug-resistant and extensive drug-resistant tuberculosis. Ann Thorac Surg 2010;89: 1597-1602.

37 Naidoo R: Active pulmonary tuberculosis: experience with resection in 106 cases. Asian Cardiovasc Thorac Ann 2007;15:134-138.

38 Pomerantz M, Madsen L, Goble M, Iseman M: Surgical management of resistant mycobacterial tuberculosis and other mycobacterial pulmonary infections. Ann Thorac Surg 1991;52:1108-1111.

39 Pomerantz BJ, Cleveland JC Jr, Olson HK, Pomerantz M: Pulmonary resection for multidrug resistant tuberculosis. J Thorac Cardiovasc Surg 2001;121:448-453.

40 Iddriss A, Padayatchi N, Reddy D, Reddi A: Pulmonary resection for extensively drug resistant tuberculosis in Kwazulu-Natal, South Africa. Ann Thorac Surg 2012;94:381-386.

41 Sciurba FC, Ernst A, Herth FJ, Strange C, Criner GJ, Marquette CH, Kovitz KL, Chiacchierini RP, Goldin J, McLennan G; VENT Study Research Group: A randomized study of endobronchial valves for advanced emphysema. N Engl J Med 2010;363:1233-1244.

42 Klooster K, Ten Hacken N, Hartman JE, Kerstjens HAM, Van Rikxoort EM, Slebos DJ: Endobronchial valves for emphysema without interlobar collateral ventilation. N Engl J Med 2015;373:2325-2335.

43 Herth FJ, Slebos DJ, Rabe KF, Shah PL: Endoscopic lung volume reduction: an expert panel recommendation. Respiration 2016;91: 241-250.

44 Corbetta L, Montinaro F, Rogasi PG, Luppi F, Magni C, Paiano S, Tofani A, Pistolesi M: Improvement in tubercular cavities following adjuvant treatment with endobronchial valves: a case report. Int J Tuberc Lung Dis 2013;17:850-851.

45 Levin AV, Tseǐkhmakh EA, Samullenkov AM, Zimonin PE, Omel'chenko SA, Chukanov IV: Valvular bronchoblocation in the treatment of patients with disseminated drugresistant pulmonary tuberculosis (in Russian). Probl Tuberk Bolezn Legk 2007:13-16.

46 Levin AV, Tseimakh EA, Zimonin PE: The use of valvular bronchial blocking in complicated lung tuberculosis: guidelines for doctors. 2008. http://www.medlung.ru/downloads/manuals/medlung-eng.pdf.
47 Levin AV, Tsermakh EA, Zimonin PE, Omel'chenko SA, Nikolaeva OB, Krasnov DV, Skliuev SV: Use of an endobronchial valve in complex treatment of patients with infiltrative pulmonary tuberculosis (in Russian). Probl Tuberk Bolezn Legk 2008:29-32.

48 Venuta F, Anile M, Diso D, Carillo C, De Giacomo T, D’Andrilli A, Fraioli F, Rendina EA, Coloni GF: Long-term follow-up after bronchoscopic lung volume reduction in patients with emphysema. Eur Respir J 2012;39: 1084-1089.

49 Davey C, Zoumot Z, Jordan S, Carr DH, Polkey MI, Shah PL, Hopkinson NS: Bronchoscopic lung volume reduction with endobronchial valves for patients with heterogeneous emphysema and intact interlobar fissures (the BeLieVeR-HIFi trial): study design and rationale. Thorax 2015;70:288-290.

50 Herth FJ, Eberhardt R, Gompelmann D, Ficker JH, Wagner M, Ek L, Schmidt B, Slebos DJ: Radiological and clinical outcomes of using chartis to plan endobronchial valve treatment. Eur Respir J 2013;41:302-308.

51 Gompelmann D, Eberhardt R, Michaud G, Ernst A, Herth FJ: Predicting atelectasis by assessment of collateral ventilation prior to endobronchial lung volume reduction: a feasibility study. Respiration 2010;80:419-425.

52 Herzog D, Thomsen C, Poellinger A, Doellinger F, Schreiter N, Froeling V, Schuermann D, Temmesfeld-Wollbruck B, Hippenstiel S, Suttorp N, Huebner RH: Outcomes of endobronchial valve treatment based on the precise criteria of an endobronchial catheter for detection of collateral ventilation under spontaneous breathing. Respiration 2016;91:6978.

53 Gompelmann D, Eberhardt R, Slebos DJ, Brown MS, Abtin F, Kim HJ, Holmes-Higgin D, Radhakrishnan S, Herth FJ, Goldin J: Diagnostic performance comparison of the Chartis System and high-resolution computerized tomography fissure analysis for planning endoscopic lung volume reduction. Respirology 2014;19:524-530.

54 Eberhardt R, Gompelmann D, Schuhmann M, Heussel CP, Herth FJ: Complete unilateral vs partial bilateral endoscopic lung volume reduction in patients with bilateral lung emphysema. Chest 2012;142:900-908.

55 Fitzpatrick C, Floyd K: A systematic review of the cost and cost effectiveness of treatment for multidrug-resistant tuberculosis. Pharmacoeconomics 2012;30:63-80.

56 Floyd K, Hutubessy R, Kliiman K, Centis R, Khurieva N, Jakobowiak W, Danilovits M, Peremitin G, Keshavjee S, Migliori GB: Cost and cost-effectiveness of multidrug-resistant tuberculosis treatment in Estonia and Russia. Eur Respir J 2012;40:133-142.

57 Pooran A, Pieterson E, Davids M, Theron G, Dheda K: What is the cost of diagnosis and management of drug resistant tuberculosis in South Africa? PLoS One 2013;8:e54587. 